\title{
Pulse Oximeter Oxygen Saturation in Prediction of Arterial Oxygen Saturation in Liver Transplant Candidates
}

\author{
Seiyed Mohammad Ali Ghayumi ${ }^{1}$; Abolfazl Khalafi-Nezhad ${ }^{1, *}$; Zahra Jowkar ${ }^{2}$ \\ ${ }^{1}$ Department of Internal Medicine, Shiraz University of Medical Sciences, Shiraz, IR Iran \\ ${ }^{2}$ Department of Operative Dentistry, School of Dentistry, Shiraz University of Medical Sciences, Shiraz, IR Iran \\ ${ }^{*}$ Corresponding Author: Abolfazl Khalafi-Nezhad, Department of Internal Medicine, Shiraz University of Medical Sciences, Shiraz, IR Iran. Tel: +98-7116474316, Fax: +98-7116474316, \\ E-mail:khalafi@sums.ac.ir
}

Received: October 26, 2013; Revised: December 6, 2013; Accepted: February 22, 2014

\begin{abstract}
Background: Liver transplant is the only definitive treatment for many patients with end stage liver disease. Presence and severity of preoperative pulmonary disease directly affect the rate of postoperative complications of the liver transplantation. Arterial blood gas (ABG) measurement, performed in many transplant centers, is considered as a traditional method to diagnose hypoxemia. Because ABG measurement is invasive and painful, pulse oximetry, a bedside, noninvasive and inexpensive technique, has been recommended as an alternative source for the ABG measurement.

Objectives: The aim of this study was to evaluate the efficacy of pulse oximetry as a screening tool in hypoxemia detection in liver transplant candidates and to compare the results with ABGs.

Patients and Methods: Three hundred and ninety transplant candidates (237 males and 153 females) participated in this study. Arterial blood gas oxyhemoglobin saturation $\left(\mathrm{SaO}_{2}\right)$ was recorded and compared with pulse oximetry oxyhemoglobin saturation $\left(\mathrm{SpO}_{2}\right)$ results for each participants. The area under the curve (AUC) of receiver operating characteristic (ROC) curves was calculated by means of nonparametric methods to evaluate the efficacy of pulse oximetry to detect hypoxemia.

Results: Roc-derived $\mathrm{SpO}_{2}$ threshold of $\leq 94 \%$ can predict hypoxemia $\left(\mathrm{PaO}_{2}<60 \mathrm{mmHg}\right)$ with a sensitivity of $100 \%$ and a specificity of $95 \%$. Furthermore, there are associations between the ROC-derived $\mathrm{SpO}_{2}$ threshold of $\leq 97 \%$ and detection of hypoxemia $\left(\mathrm{PaO}_{2}<70\right.$ $\mathrm{mmHg}$ ) with a sensitivity of $100 \%$ and a specificity of $46 \%$. The accuracy of pulse oximetry was not affected by the severity of liver disease in detection of hypoxemia.

Conclusions: Provided that $\mathrm{SpO}_{2}$ is equal to or greater than $94 \%$, attained from pulse oximetry can be used as a reliable and accurate substitute for the $\mathrm{ABG}$ measurements to evaluate hypoxemia in patients with end stage liver disease.
\end{abstract}

Keywords: Blood Gas Monitoring, Transcutaneous; Liver Cirrhosis; Oximetry; hypoxemia; Liver Transplantation

\section{Background}

Up to now, liver transplant is the only definitive treatment for many patients with end stage liver disease (1). A variety of factors such as cardiovascular and respiratory diseases can affect the success rate of the liver transplant surgery $(2,3)$. Moreover, it has been reported that the presence and severity of preoperative pulmonary diseases directly affect the rate of postoperative complications of liver transplantation (4). One of the most common disorders of pulmonary vasculature resulting in pulmonary dysfunction among liver transplant candidates is hepatopulmonary syndrome (HPS) (5). Abnormal arterial gas exchanges caused by intra pulmonary vasodilatation, the resulting hypoxemia and/or widened alveolar-arterial oxygen gradient are HPS characteristics $(6,7)$. HPS prevalence has been reported as $16 \%$ to $33 \%$ and $10-17 \%$ in liver transplant candidates with end stage liver disease and patients with cirrhosis, respectively (8-14). Ghayumi showed that hypoxemia in cirrhotic candidates for liver transplantation had prevalence of $14 \%$, without significant change over the time $(15,16)$. The presence of HPS increases post liver transplant mortality rate, although liver transplant is the only effective treatment for HPS ( 9 , 17). It has been suggested that the presence of preoperative arterial oxygen pressure $\left(\mathrm{PaO}_{2}\right)<50 \mathrm{~mm} \mathrm{Hg}$ is associated with poor post-transplant prognosis (18). Thereby, screening for HPS is an essential preliminary in all liver transplant candidates (6). The Arterial blood gas (ABG) measurement, performed in many transplant centers, is considered as a traditional method to detect hypoxemia caused by HPS (19). Due to invasive and painful nature and possible side effects of ABGs such as hematoma, infection, aneurysm and fistula formation, some efforts

Implication for health policy/practice/research/medical education:

Due to the invasive and painful nature and possible side effects of arterial blood gas measurements in detection of hypoxemia, some efforts have been made to introduce an alternative method. In this regard, it can be useful to evaluate pulse oximetry as substitution forarterial blood gas measurements in detection of hypoxemia.

Copyright (C) 2014, Kowsar Corp;; Published by Kowsar Corp. This is an open-access article distributed under the terms of the Creative Commons Attribution License, which permits unrestricted use, distribution, and reproduction in any medium, provided the original work is properly cited. 
have been made to introduce an alternative method (2023). In this context, pulse oximetry, a bedside, noninvasive and inexpensive technique, has been evaluated as an alternative source in some studies (24). According to a study by Abrams, pulse oximetry oxyhemoglobin saturation $\left(\mathrm{SpO}_{2}\right)$ $97 \%$ or less was an indicator for mild hypoxemia $\left(\mathrm{PaO}_{2}<80\right.$ $\mathrm{mm} \mathrm{Hg}$ ), whereas $\mathrm{PaO}_{2}$ less than $60 \mathrm{mmHg}$ in all patients could be identified by $\mathrm{SpO}_{2} 94 \%$ or less (24). Similarly, Argueddas found pulse oximetry as a reliable predictor to detect the presence and severity of hypoxemia in patients with hepatopulmonary syndrome (25).

\section{Objectives}

Due to the controversial results and few numbers of studies about the establishment of pulse oximetry as a screening tool to identify hypoxemia in liver transplant candidates, the aim of this study was to evaluate the efficacy of this method to detect hypoxemia in liver transplant candidates and to compare the results with ABGs.

\section{Patients and Methods}

This was a cohort prospective study with 390 participants (237 males and 153 females). Participants were recruited from patients referred to Shiraz Transplant Center, Shiraz, Iran for preoperative liver transplant evaluation over 24 months (January 2010 to December 2012). All patients signed an informed consent, approved by the Ethical Committee of Shiraz University of Medical Sciences. Cirrhosis was diagnosed based on the histological findings or the combination of radiologic, clinical and laboratory evaluations. Physical examination, pulse oximetry, chest X-ray, pulmonary function test and simultaneous arterial blood gas measurements were checked as the respiratory function indicators for all the participants. In addition, Model for End-Stage Liver Disease (MELD) score (26) was used to determine patients hepatic cirrhosis grade. Each participant was asked to sit for 15 minutes after which a finger pulse oximeter device (Oxypleth 520A Pulse Oximeter, Novametrics, Respironics Inc., Murrysville, PA, USA) was placed on the right forefinger to measure oxygen saturation in room air. Stable oxygen saturation value was recorded after one minute of pulse oximetry as $\mathrm{SpO}_{2}$. While patients were sitting; ABG measurements (oxy hemoglobin saturation, arterial $\mathrm{O}_{2}$ pressure, $\mathrm{pH}$ and bicarbonate level) from radial arteries were performed in room air. The mean difference between $\mathrm{SpO}_{2}$ and arterial blood gas oxyhemoglobin saturation $\left(\mathrm{SaO}_{2}\right)$, considered as the bias, was calculated to determine the overestimation or underestimation of the values obtained from pulse oximetry compared to ABG measurements.

Patients were divided into two groups according to the MELD score to investigate the specificity and sensitivity of pulse oximetry to detect hypoxemia based on the severity of liver disease as follows; 1) patients with MELD score below 20, and 2) patients with MELD score equal to or greater than 20. SPSS version 18 for windows (SPSS Inc., Chicago, IL, USA) was used for data analysis. To evaluate the efficacy of pulse oximetry to detect hypoxemia in liver transplant candidates, the area under the curve (AUC) of receiver operating characteristic (ROC) curves was calculated by means of nonparametric methods. Quantitative and qualitative measurements were expressed as mean \pm SD and proportions, respectively. P value less than 0.05 was considered as statistical significant. Student's unpaired t-test and chi-square test or Fisher's exact test was used to detect group differences and categorical variable differences, respectively. Non-parametric analysis (Spearman's correlation test) was used to assess the association between bias values and other patient's data.

\section{Results}

This study consisted of 390 participants as seen in Table 1, including 237 (70\%) males and 153 (30\%) females. The mean age of the participants was $43.5 \pm 13$.7. The most common causes of liver disease were cryptogenic (25.4\%) and hepatitis B (23.3\%). The average MELD score of the study was $18.3 \pm 5.2$. Abnormal chest $x$-ray findings were seen in 80 patients $(20.8 \%)$ including elevated diaphragm in 40 patients (10.3\%), pleural effusion in 28 patients (7.2\%) and other types of abnormalities in 12 patients (3.1\%). In pulmonary function tests, obstructive lung disease, considered as forced expiratory volume in 1 second/forced vital capacity $<70 \%$, was found in 29 patients (7.4\%) (Table 1 ).

The mean MELD scores were $19 \pm 5.1$ and $18.3 \pm 5.2$ for males and females, respectively. An overestimation in pulse oximetry was seen in $63.8 \%$ of the patients, and the mean bias was $1.48 \% \pm 2.85 \%$ (ranged $-7 \%$ to $14 \%$ ) (Table 2 ). Data statistical analysis revealed mean bias over $4 \%$ or less than $-4 \%$ in $12.1 \%$ ( $n=47$ ) of cases. Comparing several parameters to find potential contributory factors to the bias 4 revealed that there were no statistically significant differences between the bias 4 and chest $x$-ray abnormalities, age, $\mathrm{PaO}_{2}$, MELD score, smoking, causes of liver disease, and pH. However, the marked bias was related to the PFT pattern ( $\mathrm{P}=$ $0.018)$, gender $(\mathrm{P}=0.001)$ and $\mathrm{HCO}_{3}(\mathrm{P}=0.03)$.

To identify the sensitivity and specificity of $\mathrm{SpO}_{2}$ levels to predict hypoxemia, ROC curves were created to calculate the AUC and to determine the $\mathrm{SpO}_{2}$ cutoffs for detecting hypoxemia. Roc-derived $\mathrm{SpO}_{2}$ threshold of $\leq 94 \%$ could predict hypoxemia and a $\mathrm{PaO}_{2}<60 \mathrm{mmHg}$ with a sensitivity of $100 \%$ and a specificity of $95 \%$, with an AUC of 0.99 ( $95 \%$ confidence interval (CI), 0.98-1.00) (Figure 1). Also, there were some associations between the ROC-derived $\mathrm{SpO}_{2}$ less than $97 \%$ and detection of hypoxemia and $\mathrm{PaO}_{2}<70 \mathrm{mmHg}$ with a sensitivity of $100 \%$ and a specificity of $46 \%$, with an AUC of 0.91 (95\%CI, 0.87-1.00)(Table 3) (Figure 1).

To detect hypoxemia $\left(\mathrm{PaO}_{2}<60 \mathrm{mmHg}\right)$ in patients with MELD score equal to or greater than $20 \mathrm{mmHg}$, ROCderived $\mathrm{SpO}_{2}$ threshold of $\leq 93 \%$ had a sensitivity of $100 \%$ 
and a specificity of $95 \%$ with AUC of $0.98(95 \%$ CI,0.95-1.00). Based on the results of the constructed ROC curves, pulse oximetry was able to detect hypoxemia $\left(\mathrm{PaO}_{2}<60 \mathrm{mmHg}\right)$ with a threshold of $\leq 94 \%$ in patients with MELD score lesser than $20 \mathrm{mmHg}$ with a sensitivity of $100 \%$ and a specificity of 95\% with AUC of 0.99 (95\%CI, 0.98-1.00) (Table 4).

\section{Discussion}

Performed to evaluate the ability of pulse oximetry to detect hypoxemia in a group of patients with end stage

\begin{tabular}{lc}
\hline \multicolumn{2}{|l}{ Table 1. Demographics and Laboratory Data of the Patients } \\
\hline Variable & Value \\
\hline Age, $\mathbf{y}(\mathbf{1 6}-\mathbf{8 1})$ & $43.5 \pm 13.7$ \\
\hline Sex, Male/Female & $237 / 153$ \\
\hline MELD & $18.3 \pm 5.2$ \\
\hline Cause of cirrhosis & \\
\hline Cryptogenic & $99(25.4)$ \\
\hline Hepatitis B & $91(23.3)$ \\
\hline Autoimmune hepatitis & $43(11)$ \\
\hline Hepatitis C & $40(10.3)$ \\
\hline Primary sclerosing cholangitis & $39(10)$ \\
\hline Nonalcoholic fatty liver & $30(7.7)$ \\
\hline Alcoholic cirrhosis & $8(2)$ \\
\hline Wilson & $5(1.3)$ \\
\hline Miscellaneous & $35(9)$ \\
\hline Abnormal chest x-ray & 21.6 \\
\hline Pulmonary function test & 57.4 \\
\hline Normal & 33.3 \\
\hline Restrictive & 7.5 \\
\hline Obstructive & 1 \\
\hline Mixed & 0.8 \\
\hline Not available & \\
\hline bata are presented as mean \pm SD, No. (\%) or \%. & \\
\hline Abbreviations: MELD, model for End-Stage Liver Disease. & \\
\hline
\end{tabular}

Table 2. ABG and Pulse Oximetry Results and Calculated Bias ${ }^{\text {a }}$

\begin{tabular}{lccc}
\hline Measurement & Mean \pm SD & Range & 95\% CI \\
\hline $\mathbf{p H}$ & $7.46 \pm 0.44$ & $7.31-7.60$ & $7.46-7.47$ \\
$\mathbf{P a O}_{2}$ & $77.13 \pm 13.85$ & $40-100$ & $75.68-78.58$ \\
$\mathbf{P a C O}_{2}$ & $29.28 \pm 4.85$ & $17-46$ & $28.7-29.7$ \\
$\mathrm{HCO}_{3}$ & $21.01 \pm 3.49$ & $10-31$ & $20.6-21.3$ \\
$\mathrm{SaO}_{2}$ & $95.19 \pm 3.22$ & $74-99$ & $94.8-95.5$ \\
$\mathrm{SpO}_{2}$ & $96.1 \pm 2.96$ & $80-100$ & $95.8-96.4$ \\
Bias & $1.48 \pm 2.85$ & $-7-14$ & $1.20-1.77$ \\
\hline
\end{tabular}

a Abbreviation: CI, confidence interval. liver cirrhosis who referred for liver transplantation.

According to the results of this study, we could predict hypoxemia $\left(\mathrm{PaO}_{2}<60 \mathrm{mmHg}\right)$ with a sensitivity of $100 \%$ and a specificity of $95 \%$ with a $\mathrm{SpO} 2 \leq 94 \%$. Also, with a $\mathrm{SpO}_{2}<97 \%$, we could detect $\mathrm{PaO}_{2}<70 \mathrm{mmHg}$ with a sensitivity of $100 \%$ and a specificity of $46 \%$. Soluble components (oxyhemoglobin) detection by transmitting a specific wavelength of light (660 to $940 \mathrm{~nm}$ ) across a solution followed by measuring its intensity on the other side is the basis of pulse oximetry (27).

Table 3. Test Performance Characteristics of $\mathrm{SpO}_{2}$ Measurement as Screening Tool for Hypoxemia

\begin{tabular}{lcc}
\hline $\begin{array}{l}\mathbf{S p O}_{2} \\
\text { "positive" } \leq \text { to }\end{array}$ & $\begin{array}{c}\mathbf{P a O}_{2}<\mathbf{7 0 ~} \mathbf{m m ~ H g}, \\
\text { sensitivity [\%]/speci- } \\
\text { ficity[\%] }\end{array}$ & $\begin{array}{c}\mathbf{P a O}_{2}<\mathbf{6 0 ~} \mathbf{~ m m ~ H g}, \\
\text { sensitivity [\%]/speci- } \\
\text { ficity[\%] }\end{array}$ \\
\hline $\mathbf{8 8} \%$ & $9 / 100$ & $17 / 100$ \\
$\mathbf{8 9} \%$ & $12 / 100$ & $23 / 100$ \\
$\mathbf{9 0} \%$ & $22 / 99.3$ & $41 / 99$ \\
$\mathbf{9 1} \%$ & $36 / 99$ & $67 / 98$ \\
$\mathbf{9 2} \%$ & $47 / 98$ & $87 / 97$ \\
$\mathbf{9 3} \%$ & $55 / 97$ & $97 / 96$ \\
$\mathbf{9 4} \%$ & $61 / 96$ & $100 / 95$ \\
$\mathbf{9 5} \%$ & $68 / 91$ & $100 / 89$ \\
$\mathbf{9 6} \%$ & $86 / 79$ & $100 / 73$ \\
$\mathbf{9 7} \%$ & $100 / 46$ & $100 / 41$ \\
$\mathbf{9 8} \%$ & $100 / 8$ & $100 / 8$ \\
$\mathbf{9 9} \%$ & $100 / 1$ & $100 / 1$ \\
$\mathbf{1 0 0} \%$ & $100 / 0$ & $100 / 0$ \\
\hline
\end{tabular}

Table 4. Test Performance Characteristics of $\mathrm{SpO}_{2}$ Measurement as Screening Tool for Detection of Hypoxemia Based on the MELD Score $^{\mathrm{a}}$

\begin{tabular}{|c|c|c|}
\hline $\begin{array}{l}\mathrm{SpO}_{2} \text { "Positive" } \\
\leq \text { to }\end{array}$ & $\begin{array}{l}\mathrm{PaO}_{2}<60 \mathrm{~mm} \\
\mathrm{Hg}, \text { Sensitivity [\%]/Spec- } \\
\text { ificity[\%] MELD }<\mathbf{2 0}\end{array}$ & $\begin{array}{l}\mathrm{PaO}_{2}<60 \mathrm{~mm} \mathrm{Hg} \\
\text { - Sensitivity }[\%] / \text { Speci- } \\
\text { ficity[\%] MELD } \geq 20\end{array}$ \\
\hline $\mathbf{8 9} \%$ & $25 / 100$ & $21 / 100$ \\
\hline 90\% & $37 / 100$ & $47 / 98$ \\
\hline 91\% & $66 / 99$ & $68 / 98$ \\
\hline 92\% & $85 / 98$ & $89 / 97$ \\
\hline 93\% & $96 / 97$ & $100 / 95$ \\
\hline 94\% & $100 / 95$ & $100 / 92$ \\
\hline 95\% & $100 / 90$ & $100 / 88$ \\
\hline $96 \%$ & $100 / 72$ & $100 / 74$ \\
\hline $\mathbf{9 7} \%$ & $100 / 41$ & $100 / 41$ \\
\hline 98\% & $100 / 8$ & $100 / 8$ \\
\hline 99\% & $100 / 2$ & $100 / 5$ \\
\hline $100 \%$ & $100 / 0$ & $100 / 0$ \\
\hline
\end{tabular}

a Abbreviation: MELD, model for End-Stage Liver Disease. 


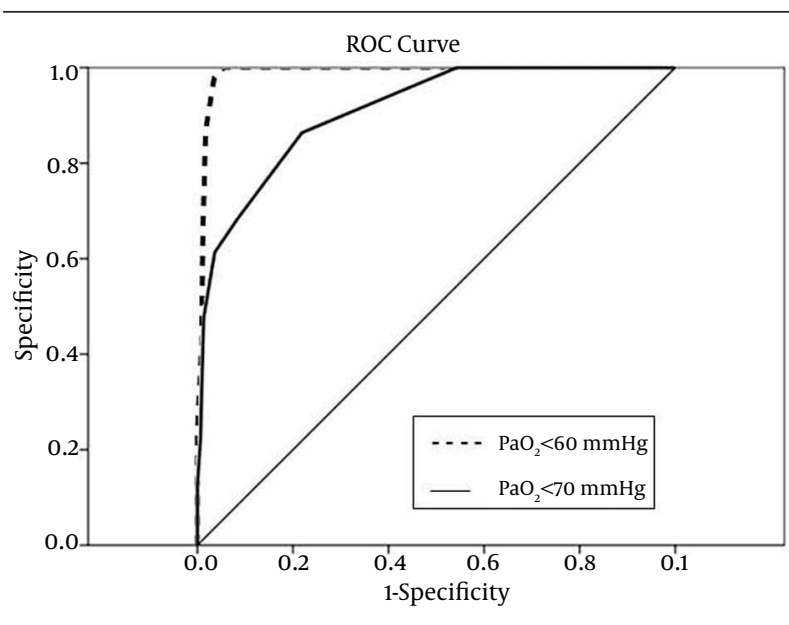

Figure 1. ROC Curves of $\mathrm{SpO}_{2}$ Measurement for the Detection of $\mathrm{SpO}_{2}<60$ $\mathrm{mm} \mathrm{Hg}$ and $\mathrm{SpO}_{2}<70 \mathrm{mmHg}$

Studies on pulse oximetry accuracy have shown contradictory results. The results of this study were consistent with some previous investigations. Abrams's study revealed that $\mathrm{SpO}_{2}$ equal to or below $97 \%$ is an indicator for mild hypoxemia $\left(\mathrm{PaO}_{2}<80 \mathrm{mmHg}\right)$; whereas, $\mathrm{PaO}_{2}$ less than $60 \mathrm{mmHg}$ in all patients can be identified by $\mathrm{SpO}_{2} 94 \%$ or less (24). However, based on the results of Abrams's study, $\mathrm{SpO}_{2}$ threshold of $\leq 94 \%$ can predict hypoxemia and $\mathrm{PaO}_{2}<70 \mathrm{mmHg}$ with a sensitivity of $68 \%$ and a specificity of $99 \%$ (24). According to Argueddas, pulse oximetry was a reliable predictor to detect the presence and severity of hypoxemia in patients with hepatopulmonary syndrome. His study also showed that a threshold value for pulse oximetry of less than $94 \%$ could identify partial pressure of oxygen < $60 \mathrm{mmHg}$ with a sensitivity and specificity of $100 \%$ and $93 \%$, respectively, which is in agreement with our results. However, this study was performed in a center near the sea level. Considering the effect of altitude on $\mathrm{SpO}_{2}$ and $\mathrm{PaO}_{2}$ values, the results of this study could not be generalized to higher altitudes (25).

In contrast, some studies did not support pulse oximetry alone as a predictor of hypoxemia. According to Blasidell, pulse oximetry had poor specificity to detect hypoxemia in clinically stable patients with sickle cell anemia in outpatient setting (28). Perkins found that $\mathrm{SpO}_{2}$ cannot reliably detect equivalent changes in $\mathrm{SaO}_{2}$ by pulse oximetry in critically ill patients (29). According to a study conducted by Bourdelles in adult emergency department, pulse oximetry reduced the number of unjustified ABG determinations. However, pulse oximetry did not affect beneficial ordering of ABG measurements (30).

According to our investigation, provided that $\mathrm{SpO}_{2}$ is equal to or greater than $94 \%$, pulse oximetry can be used as a substitute for ABG measurement to evaluate hypoxemia in patients with end stage liver disease. Although ABG measurement is performed in many transplant centers, it is considered as an invasive and painful procedure with possible side effects such as hematoma, infection, aneurism and fistula formation (20-23). Based on the results of this study, pulse oximetry, a simple bedside noninvasive and inexpensive low cost technique (24), can be used as a reliable alternative method to ABG measurement. Despite the benefits of pulse oximetry, some limitations such as light scattering and reflection, carboxyhemoglobin and methemoglobin, calibration, vasoconstriction and venous engorgement, motion artifact, hypothermia, hypotension, and anemia affect its accuracy (31-33).

Other factors, such as high blood lipid concentrations, hyper alimentation, and hyper bilirubinemia, can interfere with pulse oximeter readings. Moreover, increased concentrations of bilirubin can overestimate the measured oxygen saturation. Other influencing factors on the accuracy of pulse oximetry readings are intravenous dyes, such as methylene blue, indigocarmine and indocyanine green, artificial nails and opaque nail finishes. In contrast, skin color is not considered as a limiting factor on the accuracy of pulse oximetry, which is because of using arterial pulsatile component of blood flow by the measurements and factoring out the surrounding tissue by the microcomputer (34). However, skin color was mentioned as a limiting factor in another study (35). In our study, patients were divided into two groups according to the MELD score to detect hypoxemia based on the severity of liver disease as follows; 1 ) patients with MELD score lesser than 20 and 2) patients with MELD score equal to or greater than 20. However, the accuracy of pulse oximetry in detecting hypoxemia was not different between the two groups.

The specificity and sensitivity of pulse oximetry to detect hypoxemia in this study were high. As a result, pulse oximetry is considered as a screening tool to detect hypoxemia in patients with liver cirrhosis candidates for liver transplantation. As mentioned above, an overestimation in pulse oximetry was present in $63.8 \%$ of the patients, and the mean bias was $1.48 \% \pm 2.85 \%$ ( ranged- $7 \%$ to $14 \%)$.

Although this study was performed in a relatively high altitude center (1500 meters above the sea level), the results were approximately similar to a previous study (24) performed in a center near the sea level. Thus, it seems that altitude did not affect the accuracy of pulse oximetry in detection of hypoxemia. A relatively high number of participants (390) took part in this study. Hence, it seems that the results of this study can be reliable to be applied in other liver transplant centers. However, this study was conducted on whites and the influence of race and skin color on the accuracy of pulse oximetry is still controversial and additional studies should be assigned. 
According to the results of this investigation, provided that $\mathrm{SpO}_{2}$ is equal to or greater than $94 \%$, pulse oximetry can be used as a reliable and accurate substitute for the ABG measurements to evaluate hypoxemia in candidates for liver transplantation. In patients with $\mathrm{SpO}_{2}$ values less than $94 \%$, pulse oximetry alone is not reliable to detect hypoxemia due to overestimation of $\mathrm{SpO}_{2}$, so that detection of hypoxemia in those patients still requires $A B G$ measurement. Hence, ABG measurements should be confined to those with pulse oximetry saturation less than $94 \%$.

\section{Acknowledgements}

The authors thank the vice-chancellery of Shiraz University of Medical Sciences for supporting this research (Grant \#90-01-01-4175). This article was based on a thesis performed by Dr. Abolfazl Khalafi-Nezhad. The authors also thank Dr. Peyman Jafari, from Shiraz University of Medical Sciences for the statistical analysis and acknowledge the support of Shiraz University of Medical Sciences Liver Transplant Center.

\section{Authors' contribution}

Dr. Seiyed Mohammad Ali Ghayumi developed the study concept and design and had role in all other parts of the study. Dr. Abolfazl Khalafi-Nezhad and Dr. Zahra Jowkar had role in all parts of the study except developing the study concept and design.

\section{Financial Disclosure}

This is to certify that Dr. Seiyed Mohammad Ali Ghayumi, Dr. Abolfazl Khalafi-Nezhad and Dr. Zahra Jowkar, the authors of the manuscript entitled "Pulse oximeter oxygen saturation in prediction of arterial oxygen saturation in liver transplant candidates", did not have any commercial association or financial interest in the publication of this manuscript.

\section{Funding/Support}

This study was supported in part by a grant number 9001-01-4175 from Shiraz University of Medical Sciences.

\section{References}

1. Cardenas A, Gines P. Management of complications of cirrhosis in patients awaiting liver transplantation. $J$ Hepatol. 2005;42 Suppl(1):S124-33.

2. Johnston SD, Morris JK, Cramb R, Gunson BK, Neuberger J. Cardiovascular morbidity and mortality after orthotopic liver transplantation. Transplantation. 2002;73(6):901-6.

3. Durán FG, Piqueras B, Romero M, Carneros JA, de Diego A, Salcedo $\mathrm{M}$, et al. Pulmonary complications following orthotopic liver transplant. Transplant Int. 1998;11(1):S255-9.

4. McAlister FA, Bertsch K, Man J, Bradley J, Jacka M. Incidence of and risk factors for pulmonary complications after nonthoracic surgery. Am J Respir Crit Care Med. 2005;171(5):514-7.

5. Pham DM, Subramanian R, Parekh S. Coexisting hepatopulmonary syndrome and portopulmonary hypertension:implications for liver transplantation. J Clin Gastroenterol. 2010;44(7):e136-40.
6. Rodriguez-Roisin R, Krowka MJ, Herve P, Fallon MB, E. R. S. Task Force Pulmonary-Hepatic Vascular Disorders Scientific Committee . Pulmonary-Hepatic vascular Disorders (PHD). Eur Respir J. 2004;24(5):861-80.

7. Fallon MB, Abrams GA. Pulmonary dysfunction in chronic liver disease. Hepatology. 2000;32(4 Pt 1):859-65.

8. Martinez GP, Barbera JA, Visa J, Rimola A, Pare JC, Roca J, et al. Hepatopulmonary syndrome in candidates for liver transplantation. JHepatol. 2001;34(5):651-7.

9. Schenk P, Schoniger-Hekele M, Fuhrmann V, Madl C, Silberhumer G, Muller C. Prognostic significance of the hepatopulmonary syndrome in patients with cirrhosis. Gastroenterology. 2003;125(4):1042-52.

10. Lima BL, Franca AV, Pazin-Filho A, Araujo WM, Martinez JA, Maciel BC, et al. Frequency, clinical characteristics, and respiratory parameters of hepatopulmonary syndrome. Mayo Clin Proc. 2004;79(1):42-8.

11. Fallon MB, Krowka MJ, Brown RS, Trotter JF, Zacks S, Roberts KE, et al. Impact of hepatopulmonary syndrome on quality of life and survival in liver transplant candidates. Gastroenterology. 2008;135(4):1168-75.

12. Lenci I, Alvior A, Manzia TM, Toti L, Neuberger J, Steeds R. Saline contrast echocardiography in patients with hepatopulmonary syndrome awaiting liver transplantation. J Am Soc Echocardiogr. 2009;22(1):89-94.

13. Abrams GA, Jaffe CC, Hoffer PB, Binder HJ, Fallon MB. Diagnostic utility of contrast echocardiography and lung perfusion scan in patients with hepatopulmonary syndrome. Gastroenterology. 1995;109(4):1283-8.

14. Moller S, Krag A, Madsen JL, Henriksen JH, Bendtsen F. Pulmonary dysfunction and hepatopulmonary syndrome in cirrhosis and portal hypertension. Liver Int. 2009;29(10):1528-37.

15. Ghayumi SM, Mehrabi S, Zamirian M, Haseli J, Bagheri Lankarani K. Pulmonary complications in cirrhotic candidates for liver transplantation. Hepat Mon. 2010;10(2):105-9.

16. Ghayumi SM, Mehrabi S, Hoseini Asl M. Evolution of gas exchange abnormalities in patients with liver cirrhosis candidate for liver transplantation. Iran Red Crescent Med J. 2012;14(3):171-3.

17. Swanson KL, Wiesner RH, Krowka MJ. Natural history of hepatopulmonary syndrome: Impact of liver transplantation. Hepatology. $2005 ; \mathbf{4 1}(5): 1122-9$.

18. Arguedas MR, Abrams GA, Krowka MJ, Fallon MB. Prospective evaluation of outcomes and predictors of mortality in patients with hepatopulmonary syndrome undergoing liver transplantation. Hepatology. 2003;37(1):192-7.

19. Roberts DN, Arguedas MR, Fallon MB. Cost-effectiveness of screening for hepatopulmonary syndrome in liver transplant candidates. Liver Transpl. 2007;13(2):206-14.

20. Harrison AM, Lynch JM, Dean JM, Witte MK. Comparison of simultaneously obtained arterial and capillary blood gases in pediatric intensive care unit patients. Crit Care Med.1997;25(11):1904-8.

21. Dar K, Williams T, Aitken R, Woods KL, Fletcher S. Arterial versus capillary sampling for analysing blood gas pressures. BMJ. 1995;310(6971):24-5.

22. Kelly AM, McAlpine R, Kyle E. Venous pH can safely replace arterial $\mathrm{pH}$ in the initial evaluation of patients in the emergency department. Emerg Med J. 2001;18(5):340-2.

23. Eizadi-Mood N, Alfred S, Yaraghi A, Huynh C, Moghadam AS. Comparison of arterial and capillary blood gas values in poisoning department assessment. Hum Exp Toxicol. 2009;28(10):665-70.

24. Abrams GA, Sanders MK, Fallon MB. Utility of pulse oximetry in the detection of arterial hypoxemia in liver transplant candidates. Liver Transpl. 2002;8(4):391-6.

25. Arguedas MR, Singh H, Faulk DK, Fallon MB. Utility of pulse oximetry screening for hepatopulmonary syndrome. Clin Gastroenterol Hepatol. 2007;5(6):749-54.

26. Botta F, Giannini E, Romagnoli P, Fasoli A, Malfatti F, Chiarbonello $\mathrm{B}$, et al. MELD scoring system is useful for predicting prognosis in patients with liver cirrhosis and is correlated with residual liver function: a European study. Gut. 2003;52(1):134-9.

27. Tremper KK, Barker SJ. Pulse oximetry. Anesthesiology. 1989;70(1):98-108. 
28. Blaisdell CJ, Goodman S, Clark K, Casella JF, Loughlin GM. Pulse oximetry is a poor predictor of hypoxemia in stable children with sickle cell disease. Arch Pediatr Adolesc Med. 2000;154(9):900-3.

29. Perkins GD, McAuley DF, Giles S, Routledge H, Gao F. Do changes in pulse oximeter oxygen saturation predict equivalent changes in arterial oxygen saturation? Crit Care. 2003;7(4):R67.

30. Le Bourdelles G, Estagnasie P, Lenoir F, Brun P, Dreyfuss D. Use of a pulse oximeter in an adult emergency department: impact on the number of arterial blood gas analyses ordered. Chest. 1998;113(4):1042-7.

31. Wilkins CJ, Moores M, Hanning CD. Comparison of pulse oximeters: effects of vasoconstriction and venous engorgement. $\mathrm{Br}$
Anaesth.1989;62(4):439-44

32. Lee S, Tremper KK, Barker SJ. Effects of anemia on pulse oximetry and continuous mixed venous hemoglobin saturation monitoring in dogs. Anesthesiology. 1991;75(1):118-22.

33. Sinex JE. Pulse oximetry: principles and limitations. Am J Emerg Med.1999;17(1):59-67.

34. Mardirossian G, Schneider RE. Limitations of pulse oximetry. Anesth Prog. 1992;39(6):194-6.

35. Feiner JR, Severinghaus JW, Bickler PE. Dark skin decreases the accuracy of pulse oximeters at low oxygen saturation: the effects of oximeter probe type and gender. Anesth Analg. 2007;105(6 Suppl):18-23. 